\title{
Diagnostics of intestinal parasites in light microscopy among the population of children in eastern Afghanistan
}

\author{
Krzysztof Korzeniewski ${ }^{1}$, Agata Smoleń ${ }^{2}$, Alina Augustynowicz ${ }^{1}$, Anna Lass ${ }^{3}$ \\ ${ }^{1}$ Department of Epidemiology and Tropical Medicine, Military Institute of Medicine, Gdynia, Poland \\ ${ }^{2}$ Department of Epidemiology and Methodology of Clinical Research, Medical University, Lublin, Poland \\ ${ }^{3}$ Department of Tropical Parasitology, Institute of Maritime and Tropical Medicine, Medical University, Gdańsk, Poland
}

Korzeniewski K, Smoleń A, Augustynowicz A, Lass A. Diagnostics of intestinal parasites in light microscopy among the population of children in eastern Afghanistan. Ann Agric Environ Med. 2016; 23(4): 666-670. doi: 10.5604/12321966.1226864

\begin{abstract}
Objectives. The Afghans, living in poor socioeconomic conditions, are estimated to be a community with a high rate of intestinal parasitic infections. The aim of the study was to estimate the prevalence and species of intestinal parasites among children's population in eastern Afghanistan and to present the methods of optimizing the techniques for identification of pathogens in light microscopy. The research was carried out as a part of humanitarian project Capacity building of health care system in Ghazni Province.

Materials and method. The study involved 500 children aged 7-18 attending the Share Kona and the Khuija Ali High Schools in Ghazni, eastern Afghanistan in the period November 2013-April 2014. Three stool samples were collected from each patient at 2-day intervals, the samples were fixed in $10 \%$ formalin, transported to the Military Institute of Medicine in Poland, where they were pooled and examined using five different diagnostic methods in light microscopy (direct smear in Lugol's solution, Fülleborne's flotation, decantation in distilled water, Kato-Miura thick smear, and DiaSys/PARASYS sedimentation system).

Results. Pathogenic intestinal parasites were detected in 217 patients (43.4\%), with the most common Ascaris lumbricoides (35.3\%), Giardia intestinalis (31.1\%), and Hymenolepis nana (15.7\%). The use of direct smear method allowed for the detection of intestinal parasites in 161 individuals. The application of four following testing methods has improved the detection rates of infected patients by $11.2 \%$.

Conclusions. The variety of detected intestinal pathogens in examined children's population has required the use of combination of multiple diagnostic methods in light microscopy, and finally improved the detection rates of intestinal parasites and helped eliminate infections with nematodes, cestodes, trematodes, and protozoa using appropriate treatment in the study population.
\end{abstract}

- Key words

Afghanistan, intestinal parasites, light microscopy

\section{INTRODUCTION}

The Afghans, living in poor socio-economic conditions, are estimated to be a community with a high rate of intestinal parasitic infections. Unfortunately, reports concerning population morbidity rates often are not confirmed by laboratory tests. Afghanistan is one of 57 countries associated with the Organization of the Islamic Cooperation, with no data available on the prevalence of intestinal parasitic infections among its inhabitants [1]. In literature, there is little information concerning infections caused by intestinal parasites in Afghan refugees in the USA and Europe. In the 1980s, an examination of 51 Afghans performed in USA showed that $32 \%$ of them were infected with Ascaris lumbricoides, Giardia intestinalis, Entamoeba histolytica, Hymenolepis nana and Trichuris trichiura [2]. According to studies performed on 5,928 of Afghan refugees between 1997 - 2003 in Sweden, 225 were infected with Giardia intestinalis [3]. One of a few parasitological researches in

Address for correspondence: Krzysztof Korzeniewski, Department of Epidemiology and Tropical Medicine, Grudzinskiego 4, 81-103 Gdynia 3, Poland

E-mail:kktropmed@wp.pl

Received: 27 September 2015; accepted: 26 September 2016
Afghanistan was performed in 2002 by the German Armed Forces health service stationed in Kabul. Among 217 local workers from the international military base (kitchen aids, translators, housekeeping personnel), 64\% were infected with intestinal helminths and protozoa, with Ascaris lumbricoides predominance observed (22.1\%) [4]. In 2003, World Health Organization workers performed a screening examination of stool samples taken from 1,001 children aged $8-15$ in 4 provinces of the country. The results confirmed the occurrence of intestinal helminthiases in $47 \%$ of the children with the predominance of Ascaris lumbricoides [5].

Since 2002, the military health service of the Polish Armed Forces has been stationed in eastern Afghanistan. Under the framework of humanitarian aid, the Polish doctors and diagnosticians were mandatorily assigned to a Forward Operating Base in Ghazni, where they carried out the collection of biological samples for parasitological research with the aim of detecting and eliminating intestinal parasitic infections in the local population.

There were some diagnostic dilemmas with reference to stool examination at the stage of morbidity control, because infections with multiple species are the norm rather than exception. There is a need for well-trained laboratory diagnosticians and quality-control measures to ascertain 
accurate, species-specific parasites diagnosis [6]. Another diagnostic problem could be the long time required for collecting stool specimens in the field, transferring them to the laboratory and preparing the slides for examination, which can result in notable underestimates of intestinal parasites burdens [7]. For diagnosing intestinal parasites with light microscopy, fast, direct methods such as faecal smear and Kato-Katz thick smear are most widely used worldwide [8]. For the detection of the soil-transmitted helminths (Ascaris lumbricoides, Trichuris trichiura, Ancylostoma duodenale/Necator americanus) the World Health Organization recommends using the Kato-Katz method based on duplicate slides [9]. Other commonly used methods include direct smear, formol-ether concentration, FLOATAC and Mini-FLOATAC. All of these techniques rely on visual examination of a small sample of stool to determine the presence and number of helminth eggs [10]. Other modern techniques employed for the detection of life cycle stages of intestinal parasites (helminths and protozoa), which were used in the presented study, include PARASYS and Fülleborne's flotation.

\section{OBJECTIVES}

The aim of the study was to estimate the prevalence and species of intestinal parasites among the population of children in eastern Afghanistan, and to present the methods of optimizing the techniques for identification of pathogens in light microscopy. The research was carried out as a part of a humanitarian project Capacity building of health care system in Ghazni Province, financed by the Polish Ministry of National Defence and realized by diagnosticians of the Epidemiology and Tropical Medicine Department in Military Institute of Medicine in Gdynia, Poland.

\section{MATERIALS AND METHODS}

Study population. In total, 500 Afghan children aged 7-18, attending the Share Kona and Khuija Ali High Schools (most of students in both schools) in Ghazni, the capital city of Ghazni Province, were surveyed in the period November 2013-April 2014. Examined students were representatives of the children inhabiting eastern Afghanistan.

Sample collection. Three stool samples were collected from each child at 2-day intervals, the samples were fixed in $10 \%$ formalin, and transported to the Military Institute of Medicine in Poland where they were pooled and examined using 5 different diagnostic methods in light microscopy: direct smear in Lugol's solution, Fülleborne's flotation, decantation in distilled water, Kato-Miura thick smear and the DiaSys/PARASYS sedimentation system. Thus, 2,500 parasitological tests were performed in total.

Laboratory procedures. The diagnostics of intestinal parasites was performed by light microscopy using 5 stool testing methods:

Direct smear in Lugol's solution. Approximately $2 \mathrm{mg}$ of stool is collected with a glass rod and applied onto a slide, a drop of Lugol's solution is then added and the material smeared on the slide. Next, a cover slide is placed on top of the preparation. This method allows for an initial analysis of non-concentrated material under correct magnification of objective $(\times 10$, then $\times 40)$.

Fülleborne's flotation. Approximately $2 \mathrm{~g}$ of stool is mixed with saturated $\mathrm{NaCl}$ solution in a test tube. $\mathrm{Next}, \mathrm{NaCl}$ solution is added to the top of the tube. A covered slide is placed on top of the tube and in contact with the suspension. After 20 minutes, the cover slide is removed with tweezers and placed wet side down on a slide. The preparation is ready for microscopic examination (objective $\times 10$ magnification). This method is best for examination of helminth eggs which are lighter than the $\mathrm{NaCl}$ solution and are pushed upwards and connect to the cover slide.

Decantation in distilled water. Approximately $2 \mathrm{~g}$ of stool is mixed thoroughly with a small amount of distilled water in a test tube. Next, water is added to the top of the tube and mixed again. The supernatant is decanted after 30 minutes and another portion of water is added. The procedure was repeated until a clear supernatant is obtained, generally 3-4 times. The sediment is then placed on a slide and stained with Lugol's solution, ready for microscopic examination (objective $\times 40$ magnification). This method is very useful for examination of protozoan parasites.

Kato-Miura thick smear. This method is used to prepare a thick smear using a colouring Kato reagent for observation in light microscopy. It is effective in screening for the eggs of intestinal parasites, especially Ascaris lumbricoides. The Kato reagent contains of $100 \mathrm{ml}$ distilled water, $100 \mathrm{ml}$ of glycerin and 3 drops of $3 \%$ malachite green. Strips of cellophane must be soaked in a well mixed Kato reagent for at least 24 hours. To examine the specimen, a bead of stool is placed onto the slide and covered with a cellophane strip. Next, it is turned over and the top of the preparation is pressed onto a paper filter and left for one hour at room temperature. The sample is then ready for examination (objective $\times 10$ magnification).

DiaSys/PARASYS sedimentation system. PARASYS is a lab station equipped with a dual-stream tube system which allows a thorough examination of the concentrated material (making it possible to observe the morphology of parasites in the suspended state, and minimize the presence of faeces and other solids). The closed (isolated) process eliminates any contact with the laboratory sample. There are 4 steps in the sample preparation process. First, the test tube is filled with $2.5 \mathrm{ml}$ of $10 \%$ formalin. Then, a drop of surfactant, usually Triton $\mathrm{X}$, is added to the tube. Next, $1 \mathrm{ml}$ of ethyl acetate is added to the mix. The last step is adding approximately $0.5 \mathrm{~g}$ of stool to the test tube and vortexing it thoroughly in order to obtain a homogeneous solution. This solution needs to be centrifuged at 1,000 RCF for 1 minute. The obtained sediment is ready for microscopic examination (objective $\times 20$ and $\times 40$ magnification).

Statistical analysis. Analysis was performed using the statistical programme StatSoft Inc. (2011) STATISTICA (data analysis software system) version 10.0. www.statsoft.com (SN JGNP3087539302AR-E) and Excel. The qualitative variables were presented with the use of count and percentage. Chisquared tests for independence were used for qualitative 
variables (with the use of Yates correction for cell counts below 10, with check of Cochrane's conditions or with Fisher's exact test respectively). A sign test was used to evaluate differences between particular methods (direct smear vs. all 5 methods). In all the calculations, the statistical significance level of $\mathrm{p}=0.05$ was used.

\section{RESULTS}

Among 500 of the study subjects - Afghan students of the Share Kona and the Khuija Ali High Schools in Ghazni, eastern Afghanistan - pathogenic intestinal parasitic infections were detected in 217 children (prevalence of infection $43.4 \%$ ). The most common pathogens detected in the studied individuals were Ascaris lumbricoides (35.3\% of infections), Giardia intestinalis (31.1\%), and Hymenolepis nana (15.7\%) (Tab. 1). 58 of the tested children were diagnosed with multiple infections, mainly ascariasis+giardiasis, ascariasis+hymenolepiasis, and giardiasis+hymenolepiasis.

The use of the basic direct smear method resulted in detection of intestinal parasites in 161 individuals. The application of another 4 testing methods improved the detection rates of infected patients by $11.2 \%$ (217 infected children). The number of infections increased from 202 when the direct smear method was used, to 286 when all 5 diagnostic methods were applied (Tab. 2). The percentage of infections detected with the use of all 5 methods in comparison to the application of a single method (direct smear) was significantly higher in cases of Ascaris lumbricoides ( $\mathrm{p}=0.000001$ ), Hymenolepis nana $(\mathrm{p}=0.00006)$, and Giardia intestinalis infection ( $\mathrm{p}=0.0002)$ (Tab. 3).

Table 1. Intestinal parasitic infections in selected children in Ghazni, eastern Afghanistan, November 2013-April 2014 ( $\mathrm{n}=500$ )

\begin{tabular}{|c|c|c|c|c|c|}
\hline Intestinal parasites & $\begin{array}{l}\text { Number of infections } \\
(n=286)\end{array}$ & $\begin{array}{l}\text { Percentage } \\
\text { of infections }\end{array}$ & $\begin{array}{l}\text { Percentage of infected } \\
\text { children }(n=217)\end{array}$ & $\begin{array}{l}\text { Percentage of tested } \\
\text { children }(n=500)\end{array}$ & Treatment \\
\hline Nematodes & 121 & 42.3 & 55.8 & 24.2 & \\
\hline Ascaris lumbricoides & 101 & 35.3 & 46.5 & 20.2 & albendazole \\
\hline Enterobius vermicularis & 12 & 4.2 & 5.5 & 2.4 & albendazole \\
\hline Ancylostoma duodenale/Necator americanus & 4 & 1.4 & 1.8 & 0.8 & albendazole \\
\hline Strongyloides stercoralis & 1 & 0.35 & 0.5 & 0.2 & albendazole \\
\hline Trichuris trichiura & 1 & 0.35 & 0.5 & 0.2 & albendazole \\
\hline Cestodes & 60 & 20.9 & 27.6 & 12.0 & \\
\hline Hymenolepis nana & 45 & 15.7 & 20.7 & 9.0 & praziquantel \\
\hline Hymenolepis diminuta & 2 & 0.7 & 0.9 & 0.4 & praziquantel \\
\hline Taenia spp. & 13 & 4.5 & 6.0 & 2.6 & praziquantel \\
\hline Trematodes & 8 & 2.8 & 3.6 & 1.6 & \\
\hline Dicrocoelium dendriticum & 6 & 2.1 & 2.8 & 1.2 & praziquantel \\
\hline Fasciola hepatica & 2 & 0.7 & 0.9 & 0.4 & triclabendazole \\
\hline Giardia intestinalis & 89 & 31.1 & 41.0 & 17.8 & metronidazole \\
\hline Entamoeba histolytica s. I. & 8 & 2.8 & 3.6 & 1.6 & metronidazole \\
\hline Number of infected children & 217 & 100.0 & 100.0 & 43.4 & \\
\hline
\end{tabular}

Table 2. Identification of intestinal parasites using 5 diagnostic methods in light microscopy in selected children in Ghazni, eastern Afghanistan, November 2013-April $2014(n=500)$

\begin{tabular}{|c|c|c|c|c|c|c|}
\hline \multirow[b]{2}{*}{ Intestinal parasites } & $\begin{array}{c}\text { Direct smear } \\
\text { in Lugol's solution }\end{array}$ & $\begin{array}{c}\text { Decantation } \\
\text { in distilled water }\end{array}$ & $\begin{array}{l}\text { Fülleborne's } \\
\text { flotation }\end{array}$ & $\begin{array}{l}\text { Kato-Miura } \\
\text { thick smear }\end{array}$ & DiaSys/ PARASYS & $\begin{array}{c}\text { TOTAL } \\
\text { (5 methods }\}\end{array}$ \\
\hline & $\begin{array}{c}\text { Number } \\
\text { of infections } \\
n=202(\%)\end{array}$ & $\begin{array}{c}\text { Number } \\
\text { of infections } \\
n=171(\%)\end{array}$ & $\begin{array}{c}\text { Number } \\
\text { of infections } \\
n=84(\%)\end{array}$ & $\begin{array}{c}\text { Number } \\
\text { of infections } \\
n=105(\%)\end{array}$ & $\begin{array}{c}\text { Number } \\
\text { of infections } \\
n=155(\%)\end{array}$ & $\begin{array}{c}\text { Number } \\
\text { of infections } \\
n=286(\%)\end{array}$ \\
\hline \multicolumn{7}{|l|}{ Nematodes } \\
\hline Ascaris lumbricoides & $75(15.0)$ & $64(12.8)$ & $48(9.6)$ & $80(16.0)$ & $55(11.0)$ & $101(20.2)$ \\
\hline Enterobius vermicularis & $6(1.2)$ & $2(0.4)$ & $5(1.0)$ & $0(0.0)$ & $3(0.6)$ & $12(2.4)$ \\
\hline Strongyloides stercoralis & $1(0.2)$ & $0(0.0)$ & $0(0.0)$ & $0(0.0)$ & $0(0.0)$ & $1(0.2)$ \\
\hline Trichuris trichiura & $0(0.0)$ & $0(0.0)$ & $1(0.2)$ & $1(0.2)$ & $0(0.0)$ & $1(0.2)$ \\
\hline Trichostrongylus spp. & $0(0.0)$ & $0(0.0)$ & $2(0.4)$ & $0(0.0)$ & $0(0.0)$ & $2(0.4)$ \\
\hline \multicolumn{7}{|l|}{ Cestodes } \\
\hline Hymenolepis nana & $27(5.4)$ & $21(4.2)$ & $20(4.0)$ & $19(3.8)$ & $22(4.4)$ & $45(9.0)$ \\
\hline Hymenolepis diminuta & $2(0.4)$ & $1(0.2)$ & $1(0.2)$ & $0(0.0)$ & $1(0.2)$ & $2(0.4)$ \\
\hline \multicolumn{7}{|l|}{ Trematodes } \\
\hline Dicrocoelium dendriticum & $3(0.6)$ & $1(0.2)$ & $1(0.2)$ & $2(0.4)$ & $1(0.2)$ & $6(1.2)$ \\
\hline Fasciola hepatica & $1(0.2)$ & $1(0.2)$ & $0(0.0)$ & $0(0.0)$ & $0(0.0)$ & $2(0.4)$ \\
\hline \multicolumn{7}{|l|}{ Protozoa } \\
\hline Giardia intestinalis & $75(15.0)$ & $72(14.4)$ & $4(0.8)$ & $0(0.0)$ & $67(13.4)$ & $89(17.8)$ \\
\hline Entamoeba histolytica s. I. & $4(0.8)$ & $3(0.6)$ & $0(0.0)$ & $1(0.2)$ & $3(0.6)$ & $8(1.6)$ \\
\hline Number of infected children & 161 & 143 & 79 & 99 & 142 & 217 \\
\hline
\end{tabular}


Table 3. Identification of intestinal parasites using direct smear and all 5 diagnostic methods in light microscopy in selected children in Ghazni, eastern Afghanistan, November 2013-April $2014(n=500)$

\begin{tabular}{|c|c|c|c|}
\hline & $\begin{array}{l}\text { Direct smear in } \\
\text { Lugol's solution }\end{array}$ & $\begin{array}{c}\text { TOTAL } \\
\text { (5 methods }\end{array}$ & \\
\hline Intestinal parasites & $\begin{array}{c}\text { Number } \\
\text { of infections } \\
n=202(\%)\end{array}$ & $\begin{array}{c}\text { Number } \\
\text { of infections } \\
n=286(\%)\end{array}$ & $\mathrm{p}$-value \\
\hline \multicolumn{4}{|l|}{ Nematodes } \\
\hline Ascaris lumbricoides & $75(15.0)$ & $101(20.2)$ & 0.000001 \\
\hline Enterobius vermicularis & $6(1.2)$ & $12(2.4)$ & 0.02 \\
\hline $\begin{array}{l}\text { Ancylostoma duodenale/ } \\
\text { Necator americanus }\end{array}$ & $2(0.4)$ & $4(0.8)$ & 0.48 \\
\hline Strongyloides stercoralis & $1(0.2)$ & $1(0.2)$ & 1 \\
\hline Trichuris trichiura & $0(0.0)$ & $1(0.2)$ & 1 \\
\hline Trichostrongylus spp. & $0(0.0)$ & $2(0.4)$ & 0.48 \\
\hline \multicolumn{4}{|l|}{ Cestodes } \\
\hline Hymenolepis Nana & $27(5.4)$ & $45(9.0)$ & 0.00006 \\
\hline Hymenolepis diminuta & $2(0.4)$ & $2(0.4)$ & 1 \\
\hline Taenia spp. & $7(1.4)$ & $13(2.6)$ & 0.04 \\
\hline \multicolumn{4}{|l|}{ Trematodes } \\
\hline Dicrocoelium dendriticum & $3(0.6)$ & $6(1.2)$ & 0.25 \\
\hline Fasciola hepatica & $1(0.2)$ & $2(0.4)$ & 1 \\
\hline \multicolumn{4}{|l|}{ Protozoa } \\
\hline Giardia intestinalis & $75(15.0)$ & $89(17.8)$ & 0.0002 \\
\hline Entamoeba histolytica s. I. & $4(0.8)$ & $8(1.6)$ & 0.13 \\
\hline Number of infected children & 161 & 217 & \\
\hline
\end{tabular}

The most effective examination among the added 4 testing methods was the Kato-Miura thick smear in detection of Ascaris lumbricoides and Dicrocoelium dendriticum, Fülleborne's flotation in the detection of Enterobius vermicularis, DiaSys/PARASYS in the detection of Hymenolepis nana and Ancylostoma duodenale/Necator americanus, and decantation in distilled water in the detection of Giardia intestinalis and Taenia spp. The variety of detected intestinal pathogens in the population of examined children required the use of a combination of multiple diagnostic methods in light microscopy. This combined application improved the detection rates of intestinal pathogens and helped eliminate infections using appropriate treatment (albendazole, metronidazole, praziquantel) in the study population (Tab. 1).

\section{DISCUSSION}

Intestinal parasites pose a significant challenge for public health and especially for children living in developing countries $[11,12]$. Infections with these parasites are highly endemic in populations with a low socio-economic status and living in poor hygiene environments [13, 14].

In this study, intestinal parasites were detected in $43.4 \%$ of Afghan children, and in other reports concerning inhabitants of Afghanistan in 47-64\% [4,5]. Parasitic infections can cause serious health problems, such as iron deficiency anaemia and growth retardation [15]. The spectrum of clinical manifestations of these infections is wide and includes asymptomatic carriage, long-lasting diarrhea, stomach ache and malnutrition [16]. The diagnostics of intestinal parasites is based mainly on light microscopy as a gold standard, which allows for the detection of different stages of intestinal parasites life cycles (cyst, oocyst, trophozoite, larva, egg) [17]. Although stool examination provides an acceptable measure of the stage of infection in highly endemic areas, there was originally hope that antigen detection would do the same at the other end of the control spectrum (i.e. in areas of very low endemicity). However, this has not been validated because antigen-detection techniques are only marginally more sensitive than stool examination. Although serology and microscopy are complementary, it cannot be emphasized enough that the integration of serological methods into national control programmes requires the development of accurate, methodologically standardized and easily applicable assays for the detection of both specific antibodies and antigens [6]. Successful detection of parasites with light microscopy is strongly associated with the diagnostic methods used, and a well-trained microscopist. The success rate will be rarely higher than $30 \%$ if the direct smear method is used by a person who is inexperienced in parasitological diagnostics. In this study, a direct smear method was performed by welltrained parasitologists in the Department of Epidemiology and Tropical Medicine, where the index of detection for this basic method amounted to $74.2 \%$. An important diagnostic problem in light microscopy could be the long time-lapse between collecting the stool specimens in the field, to examination of biological samples in the laboratory. This can result in the underestimation of parasitic infections as a result of the influence of the preservatives used for stool fixation. The limitation of this study was the 2-4 week period between collection of samples in Afghanistan and examination of the fixed biological material after its transportation to Poland. Parasitological laboratories often use concentration methods, which significantly increase the detection limit of intestinal parasites. Using several diagnostic methods is reasonable for screening studies of both populations characterized by a low infection rate (detection of single pathogens), and communities where infections occur more often (detection of all pathogens in multiple infections) [18]. The inhabitants of Afghanistan are an example of a community with a high prevalence of intestinal multiple infections. It seems that single diagnostic methods and single-dose chemotherapy (antiparasitic treatment with albendazole $400 \mathrm{mg}$ or mebendazole $500 \mathrm{mg}$, common in the Third World) may prove ineffective in the elimination of intestinal parasites in the local population [19]. The application of multiple testing methods can improve not only the detection rates of infected patients (in this study by $11.2 \%$ ) but can also help to eliminate multiple co-infections with helminths and protozoa using the right treatment. The choice of a diagnostic assay should be governed by the objective of the activity. A global assessment of diagnostic test sensitivities and their extent of variation is required to investigate the suitability of diagnostic tools for different control programmes [20]. Screening the Afghan community to optimize the process of identification and elimination of intestinal parasites was one of the humanitarian control programmes carried out in developing countries. 


\section{CONCLUSIONS}

The variety of detected intestinal pathogens in the population of examined children has required the use of a combination of multiple diagnostic methods in light microscopy, and finally improved the detection rates of intestinal parasites and helped eliminate infections with nematodes, cestodes, trematodes and protozoa, by using appropriate treatment in the study population.

\section{Acknowledgements}

This study was funded by the Polish Ministry of Defense and the Military Institute of Medicine in Poland. The authors express their thanks to Baz Mohammad Hemmat, MD (Head of Ghazni Provincial Hospital, Afghanistan) and Zia Ghul, MD (Head of the Department of Health Service in Ghazni Province, Afghanistan) for their excellent technical assistance and supervision in patient recruitment, and collection of biological samples.

\section{REFERENCES}

1. Hotez PJ. The Neglected Tropical Diseases and Their Devastating Health and Economic Impact on the Member Nations of the Organisation of the Islamic Conference. PLoS Negl Trop Dis. 2009; 3(10): e539.

2. McCaw BR, DeLay P. Demographics and Disease Prevalence of Two New Refugee Groups in San Francisco. The Ethiopian and Afghan Refugees. West J Med. 1985; 143(2): 271-275.

3. Ekdahl K, Andersson Y. Imported giardiasis: impact of international travel, immigration, and adoption. Am J Trop Med Hyg. 2005; 72(6): 825-830.

4. Scheid PL, Thoma BR. Intestinal Parasites in Afghan residents employed in Camp Warehouse, Kabul. Int J med Microbiol. 2004; 293(suppl. 38): 62 .

5. Gabrielli AF, Ramsan M, Nauman C, Tsogzolmaa D, Bojang B, Khoshal MH, et al. Soil-transmitted helminths and haemoglobin status among Afghan children in World Food Programme assisted schools. J Helminthol. 2005; 79(4): 381-384.
6. Bergquist R, Johansen MV, Utzinger J. Diagnostic dillemas in helminthology: what tools to use and when? Trends Parasitol. 2009; 25(4): 151-156.

7. Dacombe RJ, Crampin AC, Floyd S, Randall A, Nghlovu R, Bickle Q, Fine PE. Time delays between patient and laboratory selectively affect accuracy of helminth diagnosis. Trans R Soc Trop Med Hyg. 2007; 101(2): 140-145.

8. Rim JH, Chai JY, Min DY, Cho SY, Eom KS, Hong SJ, et al. Prevalence of intestinal parasite infections on a national scale among primary schoolchildren in Laos,"Parasitol Res. 2003; 91(4): 267-272.

9. World Health Organization. Prevention and control of Schistosomiasis and Soil-Transmitted Helminthiasis. Technical Report no 912, Geneva 2002.

10. World Health Organization. Bench Aids for the Diagnosis of Intestinal parasites. Geneva 1994

11. Rostami M, Tohidi F, Sharbatkhori M, Taherkhani H. Intestinal Parasitic Infection among School Children in Golestan Province, Iran. Pak J Biol Sci. 2012; 15(23): 1119-1125.

12. Warunee N, Choomanee L, Sataporn P, Rapeeporn Y, Nuttapong W, Somopong S, et al. Intestinal parasitic infections among school children in Thailand. Trop Biomed. 2007; 24(2): 83-88.

13. Bethony J, Brooker S, Albanico M, Geiger SM, Loukas A, Diemert D, Hotez PJ. Soil-transmitted helminth infections: ascariasis, trichuriasis, and hookworm. Lancet 2006; 367(9521): 1521-1532.

14. Sayyari AA, Imanzadeh F, Bagheri YSA, Karami H, Yaghoobi M. Prevalence of intestinal parasitic infections in the Islamic Republic of Iran. East Mediterr Health J. 2005; 11(3): 377-383.

15. Scolari C, Torti C, Beltrame A, Matteelli A, Castelli F, Gulletta M, et al. Prevalence and distribution of soil-transmitted helmint (STH) infections in urban and indigenous schoolchildren in Ortigueira, State of Parana, Brasil: implications for control. Trop Med Int Health 2015; 5(4): 302-307.

16. Nasiri V, Esmailnia K, Karimi G, Nasiri M, Akhavan O. Intestinal Parasitic Infections among Inhabitants of Karaj City, Tehran Province, Iran in 2006-2008. Korean J Parasitol. 2009; 47(3): 265-268.

17. M28-2A. Procedures for the Recovery and Identification of Parasites from the Intestinal Tract, Approved Guideline. Clinical and Laboratory Standards Institute, Villanova PA, 2005.

18. Garcia LS, Smith JW, Fritsche TR. Selection and use of laboratory procedures for diagnosis of parasitic infections of the gastrointestinal tract. Washington DC: ASM press, 2003.

19. Korzeniewski K, Augustynowicz A, Lass A. Deworming Campaign in Eastern Afghanistan - Prevalence of Intestinal Parasites and Adoption of Treatment Strategy. Trop J Pharm Res. 2015; 14(12): 1319-1326.

20. Nikolay B, Brooker SJ, Pullan RL. Sensitivity of diagnostic tests for human soil-transmitted helminth infections: a meta-analysis in the absence of a true gold standard. Int J Parasitol. 2014; 449(11): 765-774. 